\title{
As tarefas no ensino do francês língua estrangeira: relação com a realidade e dimensão didática
}

Évelyne Bérard ${ }^{2}$

O QECR (Quadro Europeu Comum de Referência) estabelece uma continuidade com a abordagem comunicativa e funcional na medida em que a dimensão autêntica dos discursos é priorizada, mas igualmente com a ideia de tarefas a cumprir na utilização ou na aprendizagem da língua. A dupla texto/tarefa é um dos elementos-chave da perspectiva acional desenvolvida neste documento europeu.

Definiremos essa noção de tarefa e sua relação à linguagem, questionaremos se é operacional propor uma classificação das tarefas e veremos, enfim, qual é a relação entre tarefa, realidade e ensino de uma língua estrangeira.

\section{TEXTOS AUTÊNTICOS}

A compreensão e a produção de textos, e particularmente de textos autênticos, é um elemento central na aprendizagem de uma língua estrangeira, sendo o texto definido no QECR como sequência discursiva oral ou escrita. Nós nos deteremos pouco nos debates já antigos quanto à utilização do autêntico, assinalaremos alguns pontos que nos parecem marcantes. É evidente que as dificuldades subsistem quanto à coleta e à seleção de documentos; o enraizamento em situações sociais, a presença de numerosas referências ligadas ao domínio do uso da língua ou aos elementos socioculturais pode representar obstáculos para o docente e para o discente. É possível então encontrar dificuldades para organizar os documentos de modo que eles

\footnotetext{
1 Tradução em português do texto Les tâches dans l'enseignement du FLE: rapport à la réalité e dimension didactique. 2009, feita por Weslin de Jesus Santos Castro que é licenciado em Letras Português/Francês pela Universidade Federal de Sergipe. Professor e coordenador pedagógico da Aliança Francesa de Aracaju. Professor da rede pública de ensino do Estado de Sergipe. e-mail: ws_weslin@yahoo.com.br. telefone: (79) 88515814. Tradução revista por Renilson Santos Oliveira que é doutor em Letras pela Universidade de São Paulo. Mestre pela mesma universidade. Graduado pela Universidade Federal de Sergipe. Professor efetivo de Língua Francesa do Departamento de Letras Estrangeiras da Universidade Federal de Sergipe e coordenador do Curso de Letras: português/ francês da mesma universidade. e-mail: renilov@ig.com.br

${ }^{2}$ Doutora em Ciências da Linguagem pela Universidade de Franche - Comté, França. Professora da mesma universidade desde 1989. Diretora do Centro de Linguística Aplicada (CLA) da mesma universidade, entre 2008 e 2013

${ }^{3}$ Em francês, CECR (Cadre Européen Commun de Référence), sigla bastante usada pelos teóricos da Didática de Línguas Estrangeiras.
} 
sejam produtivos para a aprendizagem, mas nesse caso, os referenciais trazem uma ajuda eficaz, se esses inventários forem utilizados de uma maneira flexível. Eles permitem escolher funções que serão tratadas em cada nível: a análise dos documentos e sua relação com os objetivos facilitarão as escolhas para a utilização desses suportes, na medida em que muitas vezes não é pertinente trabalhar um documento autêntico de modo exaustivo. Assim, por ocasião da compreensão de um texto no nível A2, reter-se-á a função "dar uma opinião", mas, provavelmente, não se encontrará a função “nuançar uma opinião”. Paralelamente, os inventários para as noções gerais e específicas e para os elementos de gramática delimitam os conteúdos a serem ensinados; ora, em um documento, estruturas não listadas nos referenciais certamente tendem a aparecer, o professor poderá escolher levar em conta algumas dentre elas, por exemplo, os pronomes relativos "qui, que, où" no nível A1.

As razões pelas quais um consenso se estabeleceu quanto à utilização de textos autênticos são evidentes: motivação dos discentes e familiaridade que eles podem ter com esquemas de textos conhecidos em língua materna, diversidade e disponibilidade dos documentos, possibilidade de introduzir nas sequências de aprendizagem a variação social, oportunidade de recriar um entorno real e vivo da língua estrangeira, em particular por meio das mídias e da Internet.

Mas a utilização do documento autêntico se concebe em relação às tarefas para as quais ele serve de suporte: o mesmo documento pode funcionar em níveis diferentes, com a condição de que o que é pedido aos discentes corresponda às suas competências em dado momento. A concepção e a adaptação da tarefa são, portanto, centrais em relação a um grupo de alunos e ao seu nível.

\section{TAREFAS}

\section{Definições}

O conceito de tarefa, tal como é definido no QECR, prioriza a ideia de um resultado identificável ao qual o usuário/aluno de uma língua estrangeira vai chegar através das atividades de linguagem que mobilizam sua competência comunicativa, mas utilizando igualmente suas competências gerais e suas estratégias em uma dada área e uma dada situação. Esses elementos

\footnotetext{
${ }^{4}$ Que (função de sujeito), que (função de objeto direto), onde.
} 
permitem uma renovação das atividades de aprendizagem em aula ou em contexto individual: projeto, trocas, realização coletiva ou individual. Esse modo de conceber as atividades de aprendizagem coloca o aluno no centro da relação ensino/aprendizagem de uma língua estrangeira por várias razões: o conjunto das competências do indivíduo é mobilizado e levado em conta, a competência da linguagem a comunicar é vista como um todo que engloba língua materna e línguas estrangeiras. Alguns princípios metodológicos se impõem então: não rejeitar a língua materna, utilizar as capacidades do aluno na passagem de uma língua à outra, colocá-lo em situações didáticas que requeiram uma postura ativa, e também, o recurso a competências e estratégias diversificadas.

O QECR, ao escolher colocar no cerne do uso e da aprendizagem das línguas estrangeiras a perspectiva acional, dá à noção de tarefa uma importância particular, pois a realização de tarefas é finalmente o cumprimento de toda atividade de linguagem. O QECR dá uma definição da tarefa, de linguagem ou não, centrada no resultado:

É definido como tarefa todo foco acional visado pelo ator que deve chegar a um dado resultado em função de um problema a resolver, de uma obrigação a cumprir, de um objetivo fixado. Pode-se tratar também, conforme esta definição, de deslocar um armário, escrever um livro, decidir na negociação de um contrato, jogar uma partida de cartas, pedir um prato em um restaurante, traduzir um texto em língua estrangeira ou preparar em grupo um diário de aula. 5

O termo "tarefa" em didática de línguas foi e é utilizado com diferentes acepções: associaram-se em uma corrente metodológica tarefa e resolução de problema, no termo tarefaproblema, o que é muito provavelmente a definição mais restrita. Por outro lado, a definição mais ampla que engloba todas as atividades de aprendizagem da língua é a de Breen ${ }^{6}$ :

o termo tarefa se refere em geral a um leque de projetos de trabalho que tem globalmente como objetivo facilitar a aprendizagem de uma língua — desde o simples e breve exercício até às atividades mais complexas e mais longas, tais como a resolução de problemas em grupo ou as simulações e as tomadas de decisão.

${ }_{5}$ CONSEIL DE L'EUROPE (2001), Cadre européen commum de référence pour les langues : apprendre, enseigner, évaluer, Paris, Didier, p.16.

6 Breen, M. (1987), "Learner contributions to task design”, in C. Candlin, D. Murphy (dir.), Language Learning Tasks, Englewood Cliffs NJ, Prentice-Hall. 
Para Nunan ${ }^{7}$, na sequência de vários autores (Candlin, Wright), o termo "tarefa" é definido por aquilo que a compõe: "os objetivos, os suportes, os procedimentos, o papel do professor, o papel do discente, o contexto." Estes elementos reportam à situação didática, mas também fazem referência aos documentos, aos objetivos pragmáticos. Nunan insiste no fato de que a tarefa está ligada ao sentido, que ela tem uma relação com as atividades reais, que a avaliação se faz a partir do resultado. É igualmente sobre o resultado que Willis enfatiza ${ }^{8}$ : "Nessa obra, as tarefas são sempre atividades em que o objetivo de linguagem é utilizado pelo aluno com uma meta comunicativa para atingir um resultado."

A definição dada no QECR se inscreve, portanto, na perspectiva de Nunan e Willis, pois se encontra aí igualmente a noção de resultado. É claro também que a realização de uma tarefa tornará necessário utilizar textos como suportes. Mas a autenticidade pode também se situar no nível das interações que a realização de uma tarefa supõe entre os alunos. Mangenot e Louveau formulam isso assim ${ }^{9}$ :

Atividade que não é apenas verossímil em termos de semelhança com a vida real, mas também justificada, sob o aspecto interacional na comunidade em que ela se desenrola (a aula, em geral). A tarefa é então definida como algo que deve implicar uma comunicação mais autêntica possível entre os alunos.

Nessa perspectiva, a tarefa a ser realizada se justifica, porque ela é criadora de interações e que, como na aquisição natural de uma língua, é por meio das interações que se realiza a aprendizagem.

\section{Tarefa de linguagem verbal e não verbal}

As tarefas podem demandar linguagem verbal ou não verbal; assim, uma tarefa do cotidiano, como dirigir um carro e fazer um trajeto não precisa da linguagem, mas demanda o domínio de algumas regras decorrentes do código de trânsito: reconhecimento de placas, sinalizações escritas. Elas podem também se basear unicamente na linguagem: por exemplo, telefonar para obter uma informação administrativa. Entre os dois, existe um leque de tarefas que se utilizam da linguagem de diferentes maneiras (por exemplo, fazer funcionar um aparelho a

\footnotetext{
${ }^{7}$ Nunan, D. (2004), Task Based Language Teaching, Cambrigde, Cambrigde University Press.

${ }^{8}$ Willis, J. (1996), A Framework for Task-Based Learning, Harlow, Longman.
} 
partir de um manual de instruções) e com diferentes competências (escutar, ler, falar, escrever, traduzir, interpretar, reformular).

Da mesma maneira, o resultado de uma tarefa pode ser de linguagem ou não, assim, comprar um bilhete de trem supõe passar por um certo número de atividades de linguagem, mas o resultado disso não será da ordem da linguagem.

\section{AS TAREFAS NA AULA}

É evidente que trabalhar com as tarefas na aula facilita a aprendizagem, uma vez que o estudante é colocado em situações próximas do real e que, como no comunicativo, a realização de tarefas na aula vai permitir realizá-las em seguida na vida cotidiana. Isso supõe que o discente entra nesse procedimento didático que pode ser problemático quando ele não tem nenhum contato exterior com a língua que ele aprende; por outro lado, a simulação da realidade não é a única garantia da aprendizagem, é inconcebível utilizar tarefas que demandam, por exemplo, o imaginário e a criatividade. Além disso, as tarefas propostas na aula não são idênticas àquelas da vida, pois elas não têm finalidade real, na maioria das vezes elas são simuladas, mas sua realização pode dar lugar a interações e trocas comparáveis às trocas reais. Por outro lado, o objetivo de uma tarefa é dupla: não é apenas a tarefa que é visada, mas igualmente, a correção da língua utilizada para realizá-la.

Em uma aula de língua, esta assume outro papel em relação às tarefas a efetuar. Esperar-se-ão não apenas alunos que cumprem corretamente uma tarefa, mas que, além disso, realizam-na empregando os termos apropriados e corretos da língua. É o caso mesmo das abordagens pedagógicas que consideram que as tarefas a cumprir nas aulas de línguas devem ser o reflexo fiel da "verdadeira vida" - visto que, depois de tudo - o objetivo dos cursos de língua consiste em aprender uma nova língua. Mesmo em tal abordagem, é preciso insistir tanto na aprendizagem do sistema formal da língua quanto no conteúdo de cada tarefa. 10

Desse ponto de vista, a situação de aula apresenta analogias com as conversas externas à língua, tanto em relação à aquisição quanto à dupla focalização: "Os interlocutores dirigem sua

\footnotetext{
${ }^{9}$ Mangenot, F., Louveau, E. (2006), Internet et la classe de langue, Paris, CLE International.
}

${ }^{10}$ Conseil de l'Europe (2002), Guide pour utilisateurs, site do Conselho da Europa. 
atenção de maneira alternativa ou simultânea, por um lado, ao conteúdo das mensagens, por outro lado, aos modos de formulação, transmissão, interpretação, etc. Quanto a isso, Bange (1987) fala de focalização."11

A situação de dupla focalização, inerente à aula de língua, conduz a uma deriva que consiste em dirigir toda a atenção à língua, esquecendo o resultado. Logo, fazem-se necessários um equilíbrio entre os dois polos e uma atenção diferenciada dada ao resultado ou à correção da língua, objetivo central dos exercícios.

\section{OS TIPOS DE TAREFA}

\section{Classificação}

Logo, é fácil distinguir o que decorre das tarefas e o que decorre dos exercícios, empregamos este termo para simplificar, mas poderíamos dizer também atividades linguísticas; na definição que segue, elas são chamadas de "tarefas de pré-comunicação pedagógica" que têm sempre como objetivo a manipulação das formas. O QECR distingue por outro lado as tarefas de simulação da realidade e as tarefas que se fundam na comunicação na aula como espaço social.

O QECR distingue três categorias de tarefas das quais participa o aluno de língua viva:

1. as tarefas "alvo", "de repetição" ou "próximas da vida real" escolhidas em função das necessidades do aluno fora da aula ou do contexto de aprendizagem.

2. as tarefas de comunicação pedagógica fundadas na natureza social, interativa e imediata da situação de aula, os alunos se engajam nisso em um "fazer de conta aceito voluntariamente" para atuar no jogo da utilização da língua-alvo; estas tarefas têm resultados identificáveis;

3. as tarefas de pré-comunicação pedagógica constituídas de exercícios especificamente focados na manipulação descontextualizada das formas. ${ }^{12}$

No entanto, é evidente que toda uma série de tarefas propostas na aula decorra da simulação do real, estamos realmente no "fazer de conta aceito" como regra para aprender a língua estrangeira. Mas algumas tarefas podem ter uma relação estreita com a realidade: compreender

\footnotetext{
${ }^{11}$ De Pietro, J.-F, Matthey, M., Py, B. (1988), “Acquisition et contrat didactique: les séquences potentiellement acquisitionelles dans la conversation exolingue ", in Actes $d u 3^{e}$ Colloque régional de linguistique, Strasbourg, Université des Sciences Humaines et Université Louis Pasteur.

${ }^{12}$ Ibid.
} 
um documento sonoro ou televisivo, ter uma conversa com outro aluno sobre uma experiência pessoal... Willis propõe uma classificação que faz referência a uma outra maneira de encarar a tarefa:

\section{Listar}

2. Ordenar e classificar

3. Comparar

4. Resolver um problema

5. Partilhar uma experiência pessoal

6. Participar de tarefas criativas ${ }^{13}$

Esta classificação se situa do ponto de vista do discente e se faz em função das operações cognitivas que ele deve realizar $(1,2,3,4)$, seria possível acrescentar parear, hierarquizar, que são operações próximas, ou em função da experiência e da imaginação do discente $(5,6)$. Pode-se completar essa maneira de classificar com as componentes da tarefa: suporte, papel do professor, do aluno, procedimentos e atitudes (escutar, ler, falar, escrever, traduzir, interpretar, reformular).

A utilização de uma tabela que considere esses diferentes elementos se justifica para o professor, pois ela permite fazer o aluno trabalhar com uma variedade próxima da realidade e com todos os seus componentes da competência a comunicar. A tabela que propomos abaixo tem por origem o Guide pour utilisateurs du CECR (Guia para usuários do QECR), que é uma matriz que modificamos e que pode ser aperfeiçoada. Ela constitui uma ajuda para a concepção das tarefas em função das áreas visadas e dos objetivos fixados. ${ }^{14}$

\section{Ferramenta de concepção de tarefas}

\begin{tabular}{|c|l|l|l|l|l|l|l|}
\hline & & & & & & & \\
\hline Tarefas de base & & & & & & & \\
\hline Compreender & & & & & & & \\
\hline Antecipar & & & & & & & \\
\hline Responder/Interrogar & & & & & & & \\
\hline Nomear & & & & & & & \\
\hline Parear & & & & & & & \\
\hline Transferir & & & & & & & \\
\hline Selecionar & & & & & & & \\
\hline Encontrar/Identificar & & & & & & & \\
\hline Completar & & & & & & & \\
\hline
\end{tabular}

\footnotetext{
${ }^{13}$ Willis, J. (1996), A Framework for Task-Based Learning, Harlow, Longman.

${ }^{14}$ Conseil de l'Europe (2002), Guide pour utilisateurs, p. 260.
} 


\begin{tabular}{|c|l|l|l|l|l|l|l|}
\hline & & & & & & & \\
\hline Tarefas de conceituação & & & & & & & \\
\hline Reagrupar & & & & & & & \\
\hline Classificar/Ordenar & & & & & & & \\
\hline Comparar/Opor & & & & & & & \\
\hline Deduzir/Imaginar/Inferir & & & & & & & \\
\hline Tarefas de modificação & & & & & & & \\
\hline Completar & & & & & & & \\
\hline Inserir & & & & & & & \\
\hline Corrigir & & & & & & & \\
\hline Extrair & & & & & & & \\
\hline Suprimir & & & & & & & \\
\hline Desenvolver & & & & & & & \\
\hline Continuar & & & & & & & \\
\hline Transformar/Modificar & & & & & & & \\
\hline Melhorar & & & & & & & \\
\hline & & & & & & & \\
\hline Tarefas discursivas & & & & & & & \\
\hline Descrever & & & & & & & \\
\hline Discutir & & & & & & & \\
\hline Explicar & & & & & & & \\
\hline Justificar & & & & & & & \\
\hline Argumentar & & & & & & & \\
\hline Demonstrar & & & & & & & \\
\hline
\end{tabular}

\section{Realização das tarefas e complexidade}

A dificuldade e a complexidade de uma tarefa decorrem de vários fatores: das competências que devem ser colocadas em execução para cumprir, das estratégias que o aluno deve convocar, da natureza da própria tarefa e de sua possível decomposição em etapas; por exemplo, redigir um texto argumentativo em um nível $\mathrm{C} 1$ pode incluir as seguintes tarefas:

- ler textos para estar a par do assunto

- listar as ideias pessoais sobre o tema

- fazer um plano do texto

- redigir, reler

A realização de uma tarefa coloca em execução diferentes competências:

- competências gerais que remetem ao conhecimento do mundo, à experiência do indivíduo, às suas capacidades cognitivas;

- competências para compreender textos;

- competência a comunicar, com seus componentes linguísticos, sociolinguísticos, pragmáticos e diferentes estratégias. 
A realização de tarefas também põe em prática estratégias, assim, quando se pede a um aluno para classificar elementos, ele utilizará a comparação, ele procederá por eliminação; da mesma maneira a compreensão de um documento sonoro é facilitada pela presença de elementos visuais, pelo reconhecimento de marcas de entonação, pelo conhecimento da situação apresentada, pois todos esses elementos permitem chegar ao sentido pela dedução e pela inferência.

A natureza da própria tarefa pode ser mais ou menos complexa porque ela pode requerer várias competências, porque a situação é desconhecida para o aluno, porque ele não sabe realizar em língua materna o mesmo tipo de tarefa; assim uma tarefa escolar como "apresentar um seminário" pode apresentar algumas dificuldades tanto no seu planejamento (preparação) como na sua realização, pois ela supõe que o aluno tenha conhecimentos sobre um assunto, que ele domine de maneira precisa a estruturação de um discurso, nos encadeamentos lógicos, que ponha em prática uma competência linguística, mas também que ele possua fluidez e desembaraço na produção de um discurso oral.

A complexidade procede igualmente da relação entre texto ou suporte e tarefa, assim o mesmo documento sonoro pode propiciar uma compreensão global, ou uma compreensão detalhada para uma tomada de notas. Com relação a isso, e de um modo consensual, a tendência que se encontra na maioria dos manuais que se prevalecem do QECR é a seguinte: o aluno é exposto a um conjunto de tarefas de caráter limitado, a partir de documentos autênticos ou verossímeis, e a exercícios que visam à prática da língua. Estas tarefas versam sobre diferentes componentes da competência a comunicar, por um lado, sociolinguística e mais amplamente sociocultural, e por outro lado, pragmática. O conjunto destas atividades se conclui, em geral, com uma tarefa mais complexa, nomeada, por exemplo, "projeto" no método Alors, "tarefa focada" no método Rond Point ${ }^{15}$; esta tarefa final tem um caráter real ou simulado, mas implica sempre tratar documentos, utilizar diferentes atitudes e passar por várias etapas, como organizar uma festa, escolher um lugar para as férias, etc. Este resultado implica a produção de discurso, a resolução de problemas, um resultado, como em uma situação da vida quotidiana. E, em uma certa medida, esse tipo de atividade poderia ir até a simulação global.

${ }^{15}$ Di Giura, M., Beacco, J-C. (2007), Alors, Paris, Didier et Labascoule, J., Lause, C., Royer, C. (2004), Rond Point, Diffusión. 


\section{EM CONCLUSÃO: REALIDADE DA TAREFA E USO DA LÍNGUA ESTRANGEIRA}

Os procedimentos que vão ao sentido da realização de tarefas como princípios de uma metodologia abrem igualmente uma perspectiva na relação entre realidade, utilização da língua e aprendizagem na aula. Um dispositivo de aprendizagem pode certamente incluir tarefas que simulam situações reais, que preparam a realização de tarefas reais, por exemplo, aprender a compreender um jornal televisivo na aula facilita o desenvolvimento e o reinvestimento de estratégias fora da aula. É isso que é desenvolvido em um método como Ici, concebido para uso em meio francófono. ${ }^{16}$ Mas, o desenvolvimento das TICE (Technologies de l'information et de la communication pour l'enseignement, Tecnologias da informação e de comunicação para o ensino) facilita esta prática quando a língua aprendida não é a língua de comunicação no contexto: é possível propor tarefas a efetuar sozinho ou em pequenos grupos, cujos resultados serão apresentados em aula, por exemplo, encontrar na Internet um hotel com certas informações (localização, conforto, preço), enviar uma mensagem para obter uma documentação sobre um dado produto, dar sua opinião em um fórum, etc. Trabalhar nesse sentido recria uma fluidez entre a aprendizagem e a realidade, entre a aula e o exterior, e instaura uma continuidade entre utilização da língua e sua aprendizagem, na qual o aluno pode evoluir como ator social.

\section{BIBLIOGRAFIA}

BEACCO, J.-C. L'approche par compétences dans l'enseignement des langues, Paris, Didier. 2007.

BEACCO, J.-C, BOUQUET, S., PORQUIER, R. (dir.) Niveau B2 pour le français, Un référentiel, Paris, Didier. 2004.

BÉRARD, É. L'approche communicative, Paris, CLE International. cla.univ-fcomte.fr/mediacla. 1991.

BÉRARD, Évelyne. Les tâches dans l'enseignement du FLE: rapport à la réalité et dimension didactique. Le français dans le monde: recherches et applications. Paris, n. 45, p. 36 - 44, janvier 2009.

${ }^{16}$ Abry, D., Daas, Y., Deschamps, H. (2007). Ici 2, Méthode de français niveau A2, Paris, CLE International. 
CONSEIL DE L'EUROPE. Cadre européen commum de référence pour les langues : apprendre, enseigner, évaluer, Paris, Didier. 2001.

CONSEIL DE L'EUROPE. Guide pour utilisateurs, site du Conseil de l'Europe. 2002.

GOULliER, F. Les Outils du Conseil de l'Europe en classe de langue, Paris, Didier. 2005.

NUNAN, D. Task Based Language Teaching, Cambrigde, Cambrigde University Press. 2004.

ROSEN, É. Le Point sur le Cadre Européen Commum de Référence pour les Langues, Paris,

CLE International. 2007.

WILLIS, J., A Framework for Task-Based Learning, Harlow, Longman. 1996.

Recebido: 10.07.2015

Aceito: 25.08 .2015 